\title{
ЭКОНОМИЧЕСКИЕ ИНДИКАТОРЫ КАРТИРОВАНИЯ СТРУКТУРЫ ВЫСОКОТЕХНОЛОГИЧНЫХ ОТРАСЛЕЙ ПРОМЫШЛЕННОСТИ
}

\author{
(C) 2020 Уманский Анатолий Михайлович \\ соискатель кафедры экономики и управления предприятиями и производственными комплексами \\ Санкт-Петербургский государственный экономический университет, Россия, Санкт-Петербург \\ E-mail:uam_777@mail.ru
}

В настоящей публикации представлены результаты авторского статистического эксперимента, направленного на поиск экономических индикаторов, определяющих структуру высокотехнологичных отраслей. Сформулирована теоретическая платформа эксперимента - концепция мезоэкономики, «формула Клейнера», картирование отраслей европейской научной школы Schneider M.R. Представлены результаты корреляционного анализа, обнаруживающего три взаимосвязанных индикатора для картирования отраслей высокотехнологичного сектора.

Ключевые слова: экономика, промышленность, высокие технологии.

\section{Актуальность и степень изученности проблемы.}

Вопрос экономического роста национального высокотехнологичного сектора является объективной задачей, сформулированной в рамках национальной стратегии: «...создать собственные технологии ..., которые определяют будущее ... искусственном интеллекте, генетике, новых материалах, источниках энергии, цифровых технологиях» (Путин В.В."). Решение данной задачи имеет как научно-исследовательскую, технологическую проблематику повышения результативности и эффективности инновационной деятельности, интенсификации сектора исследований и разработок, так и экономическую - поиск механизмов роста товарооборота высокотехнологичной продукции.

Поиск экономических механизмов на макро- и микроуровнях в настоящей научной дискуссии признан «тупиковым» (Henisz W.J., Swaminathan A. [1]). Исследователи сосредоточили свое внимание на выявлении системы институтов высокотехнологичного сектора: состава специализированных субъектов, их пропорций и схемы экономического взаимодействия. «... Способы моделирования институтов в международных исследованиях (высокотехнологичных отраслей), по-прежнему считаются неудовлетворительным...» Schneider M.R. и др. [2]. Фактически исследования сфокусированы на мезоуровне, изучении отрасли как экономической системы. Теоретической платформой такого направления является парадигма «мезоэкономики» «... используемая для изучения экономических механизмов, которые не основаны ни на микроэкономике покупок и продаж, а также на предложении и спросе, ни на макроэкономическом обосновании совокупных итогов спроса, но на важности того, под какими структурами эти силы действуют и как измерить эти эффекты» (Dopfer K. [3]). Применительно к высокотехнологичному сектору концепция мезоэкономики была развита в работах зарубежных авторов Paunescu M., Schneider M. [4], Dixon M. и др. [5], Kleiner M.M. [6], Boyer R. [7], Jackson G., Deeg R. [8] и других. Исследование проблем мезоэкономики в национальном научном сообществе сосредоточено в работах «Центрального экономикоматематического института РАН (ЦЭМИ РАН)». Ядром научных взглядов является «формула Клейнера»: «... фактически изучение мезоэкономических структур эквивалентно изучению институтов... Мезоэкономика - естественное поле формирования и действия экономических институтов» (Клейнер Г.Б. [9]). Активными участниками национальной научной дискуссии являются Волынский А.И. [10], Гареев Т.Р. [11], Марков Л.С., Ягольницер М.А. [12], Кирдина С.Г. [13], Ореховский П.А. [14], Гасанов Э.А., Бойко Т.С., Фролова Н.С. [15], Тишков С.В. [16] и другие.

2 подхода, сформированные в рамках научной дискуссии о мезоэкономических методах, заслуживают отдельного внимания, поскольку

\footnotetext{
" Послание Президента Путина В.В. Федеральному Собранию, 15 января 2020 года, Москва. Режим доступа: http://www.kremlin.ru/events/president/news/62582 14.02.2020.
} 
являются научными предпосылками авторского статистического эксперимента, представленного в настоящей публикации. Во-первых, понятие «институционального капитала» (англ.- institutional capital), сформулированное в работе Henisz W.J., Swaminathan A. [1]. B его основе лежит эконометрически доказанный посыл: рост и эффективность высокотехнологичных отраслей предопределится структурой и пропорциями институтов (специализированных субъектов). Во-вторых, в развитие первого тезиса Schneider M.R. [2] предложил инструментальный подход к выявлению институтов и их пропорций, получивший название «картирование институционального капитала».

Но предложенный подход к картированию имеет ограничение - построен на качественном анализе структуры высокотехнологичных отраслей. Соответственно, подход не может быть реплицирован на отрасли с отличной от исследованных Schneider M.R. системой институционального развития. Автор видит решение данной проблемы через создание системы взаимосвязанных количественных индикаторов, позволяющих выявлять и описывать (картировать) структуру высокотехнологичных отраслей.

Описание авторского эксперимента.

Целью эксперимента автор определил поиск взаимосвязанных индикаторов экономического развития высокотехнологичных отраслей, являющихся платформой для поиска дискретных значений, выделяющих (например, через математические кластеры) границ институтов.

Научный поиск, структура эксперимента, построены на следующей логике. 1) Выделить «эталонную» высокотехнологичную отрасль, доказавшую свою конкурентоспособность и экономическую эффективность на глобальном рынке. 2) Формализовать список гипотетических экономических индикаторов, отражающих рост масштаба высокотехнологичной отрасли. 3) По базе данных индикаторов провести оценку кросскорреляционных взаимосвязей. 4) Обнаруженные высокие значения по шкале Чеддока взаимосвязи показателей признать отвечающими задаче эксперимента.

Автор синтезировал соответствующий ста- тистический эксперимент. 1) В качестве эталонной автор выбрал фармацевтическую промышленность Европы, имеющую объективный уровень глобальной конкурентоспособности, финансовой и инвестиционной эффективности. 2) Формализован список гипотетических экономических индикаторов, отражающих рост масштаба высокотехнологичной отрасли (табл. 1), построенный на показателях финансовой отчетности, принятой в МСФО и сопоставимой с национальными бланками налоговой отчетности.

3) Источником данных статистического эксперимента определена база данных Aмadeus. Выборка по фармацевтической промышленности Европы на 2018 отчетный год составила 4629 предприятий, позиция которых отражена финансовыми индикаторами (табл. 1). Относительно данной выборки проведён кросскорреляционный анализ, результаты которого рассматриваются ниже.

\section{Результаты эксперимента.}

Результаты кросскорреляционного анализа гипотетических индикаторов экономического развития высокотехнологичных отраслей представлены в таблице 2 .

Высокий уровень взаимосвязи по шкале Чеддока обнаруживается в показателях:

1. величины активов;

2. списочной численности персонала;

3. операционного дохода.

Представленные на рис. 1-3 поля корреляции отражают логику взаимосвязи индикаторов, институциональную природу (групп) субъектов хозяйственной деятельности высокотехнологичных отраслей.

Поле корреляции показателей величины активов и списочной численности персонала (рис. 1) обнаруживает отрицательный тренд роста численности занятых по отношению к капитализации. Что вполне объяснимо (выводы построены на обследовании автором кейсов в базе данных Amadeus*) для высокотехнологичного сектора. Большая численность персонала характерна для производственных компаний, имеющих относительно (научно-исследовательскому сектору) низкий уровень капитализации.

Активы высокотехнологичного сектора со-

\footnotetext{
" Необходимо уточнить, что выводы автора об институциональной структуре, представленные в настоящем разделе публикации являются предварительными (построенными на кейсах). Они демонстрируют возможность картирования на основании детерминированных индикаторов, что и являлось целью авторского эксперимента. Собственно картирование институциональной структуры высокотехнологичного сектора является направлением дальнейших исследований автора и его коллег.
} 
Таблица 1. Структура выбранных гипотетических экономических индикаторов, отражающих рост масштаба высокотехнологичной отрасли.

\begin{tabular}{|l|l|}
\hline Aббр. & Поле и описание \\
\hline Comp. & $\begin{array}{l}\text { Наименование предприятия в соответствии с уставными докумен- } \\
\text { тами. }\end{array}$ \\
\hline OR & $\begin{array}{l}\text { Операционный доход (выручка) по основной хозяйственной дея- } \\
\text { тельности (исключена финансовая и инвестиционная), тыс. еuro. }\end{array}$ \\
\hline NE & Списочная численность предприятия, чел. \\
\hline BvD & $\begin{array}{l}\text { Индекс «независимости акционерного капитала». Классификация } \\
\text { Мооду's Analytics Сотрапу1 по уровню концентрации акционерного } \\
\text { капитала по структуре: численности и величине долей инвесторов } \\
\text { (от А+ до D). }\end{array}$ \\
\hline GUO & $\begin{array}{l}\text { Наименование материнской компании, мажоритарный акционер } \\
\text { предприятия. }\end{array}$ \\
\hline NI & $\begin{array}{l}\text { Чистый доход, прибыль предприятия до выплаты дивидендов, тыс. } \\
\text { еuго. }\end{array}$ \\
\hline ROE & $\begin{array}{l}\text { Рентабельность собственного капитала предприятия, отношение чи- } \\
\text { стого дохода (NI) к величине активов (TAS), \%. }\end{array}$ \\
\hline TAS & Активы, совокупность активов на балансе предприятия, тыс. еuго. \\
\hline PM & $\begin{array}{l}\text { Норма прибыли, как отношение чистого дохода (NI) к операционной } \\
\text { выручке (ОR) предприятия, \%. }\end{array}$ \\
\hline
\end{tabular}

Таблица 2. Результаты кросскорреляционного анализа гипотетических индикаторов экономического развития высокотехнологичных отраслей (обозн. переменных в табл. 1)

\begin{tabular}{|l|r|r|r|r|r|r|}
\hline & \multicolumn{1}{|c|}{ OR } & \multicolumn{1}{c|}{ NE } & \multicolumn{1}{c|}{ NI } & \multicolumn{1}{c|}{ ROE } & \multicolumn{1}{c|}{ TAS } & PM \\
\hline NE & $\mathbf{0 , 9 0 1 5 * * *}$ & & & & & \\
\hline NI & $0,4862 * *$ & $0,4524 * *$ & & & & \\
\hline ROE & 0,0150 & 0,0103 & 0,0314 & & & \\
\hline TAS & $\mathbf{0 , 9 1 1 1 * * *}$ & $\mathbf{0 , 8 7 7 8 * * *}$ & 0,4509 & 0,0041 & & \\
\hline PM & 0,0200 & 0,0178 & 0,0608 & 0,4021 & 0,0148 & \\
\hline BvD & $-0,0489$ & $-0,0646$ & $-0,0133$ & 0,0026 & $-0,0562$ & 0,0167 \\
\hline
\end{tabular}

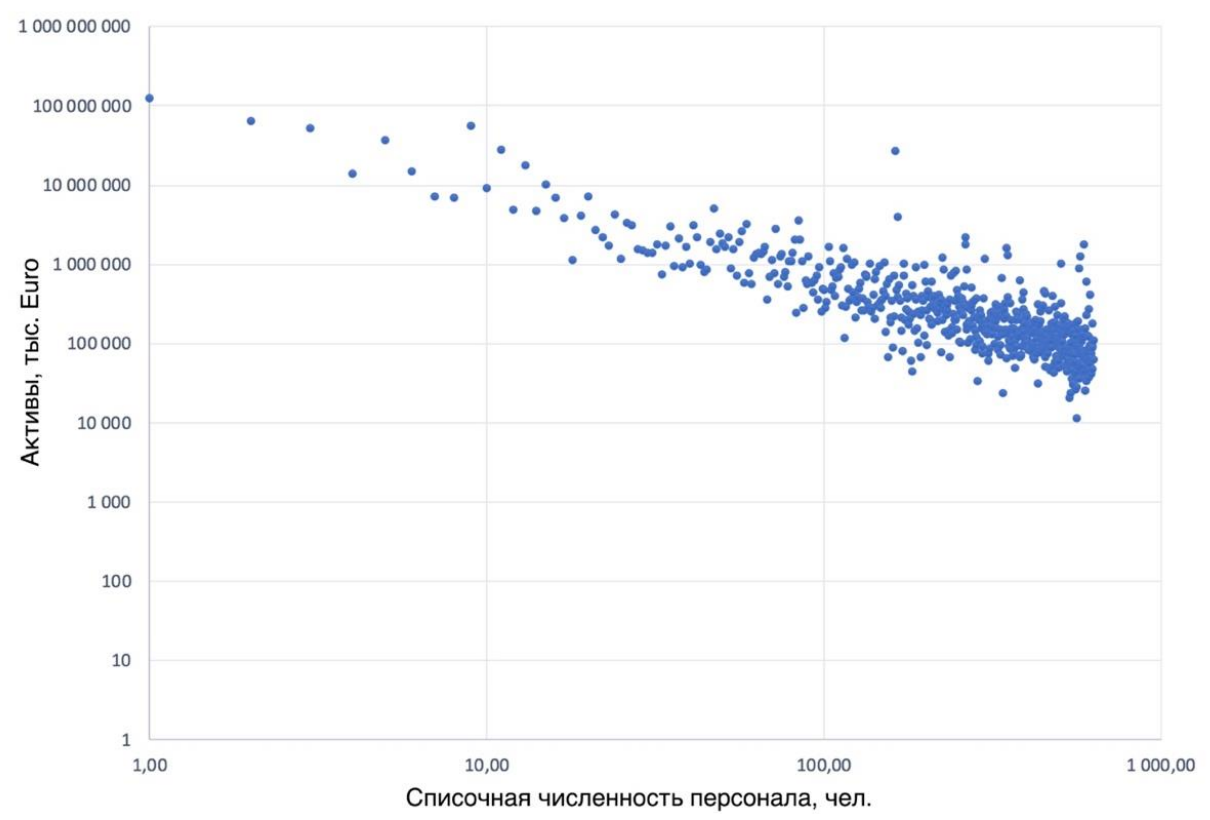

Puc. 1. Поле корреляции показателей величины активов и списочной численности персонала 


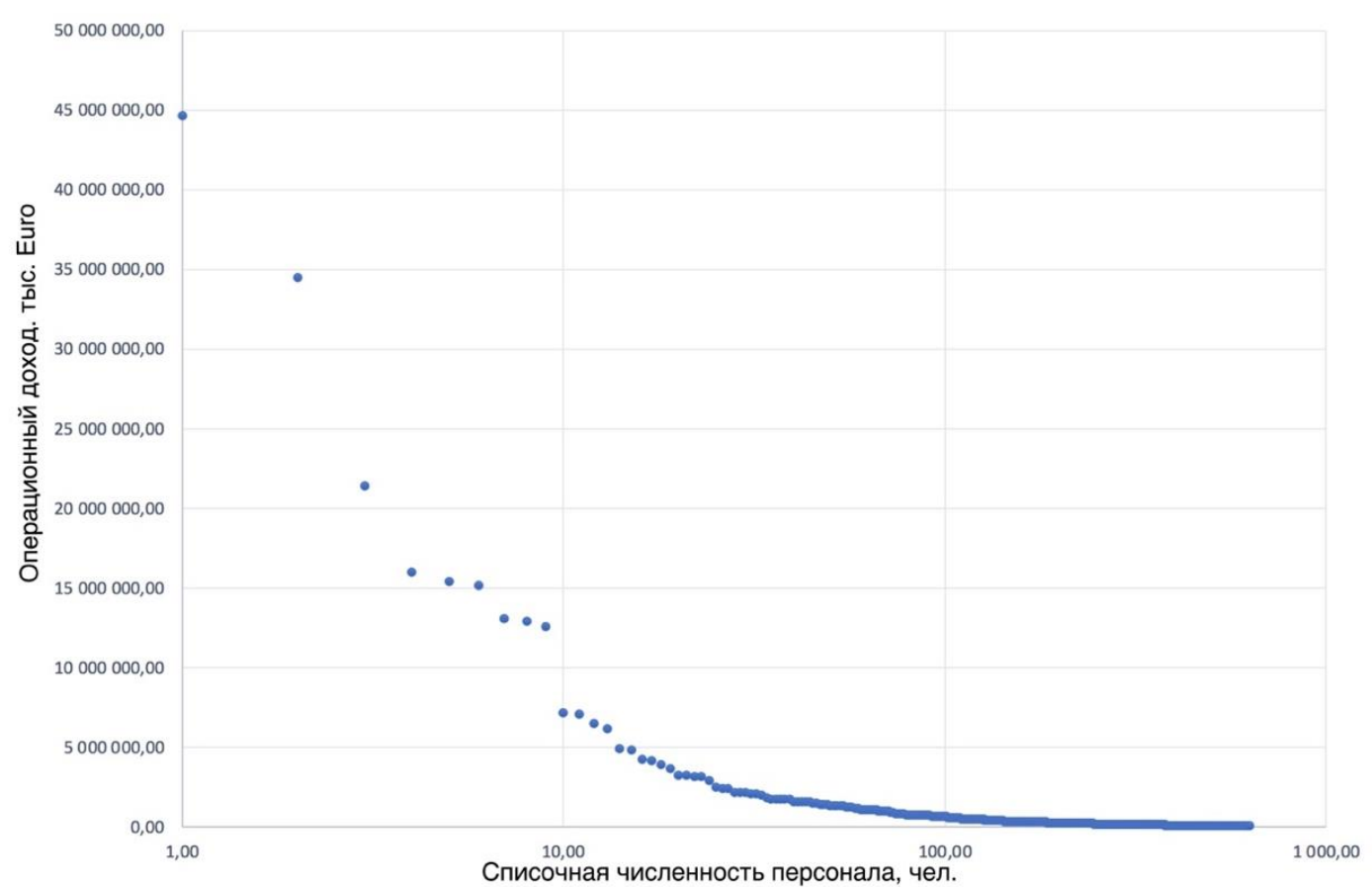

Рuc. 2. Поле корреляции показателей операционного дохода и списочной численности персонала

средоточены в интеллектуальном капитале, секторе исследований и разработок, имеющем относительно (производственному) низкую численность занятых. В кластер с низкой численностью и высоким уровнем активов вошли также корпоративные структуры (инвестиционные фонды, управляющие компании и т.п.), то есть держатели акционерного капитала высокотехнологичного сектора. Этот тезис находит свое подтверждение (помимо кейсов, изученных автором) при анализе поля корреляции показателей операционного дохода и списочной численности персонала (рис. 2). Наибольшие значения операционного дохода сосредоточены у держателей акционерного капитала - предприятиях с низкой численностью персонала. В свою очередь, исследовательские и производственные компании имеют большую численность персонала при низком операционном доходе, поскольку являются дочерними для корпоративных структур и в своей хозяйственной деятельности являются подрядчиками в иерархии контрактов высокотехнологичного сектора.

В контекст выше приведённого тезиса попадает и тренд взаимосвязи показателей величины активов и операционного дохода (рис. 3). Корпоративные структуры, консолидирующие операционный доход высокотехнологичного сектора, имеют незначительные активы, как правило, являются держателями нематериальных (ОИС). А производственные и исследовательские предприятия с низким операционным оборотом являются собственниками основных фондов (земля, основные производственные фонды и т.п.).

Таким образом, задача статистического эксперимента решена: обнаружены взаимосвязанные переменные, на основании которых возможно картирование институциональной структуры отраслей высокотехнологичного сектора.

\section{Выводы.}

Итак, научным результатом авторского эксперимента является детерминирование 3-х взаимосвязанных переменных (рис. 4), позволяющих картировать институциональную структуру высокотехнологичных отраслей.

В теоретической плоскости представленное решение направлено на развитие представлений о природе «институционального капитала» (Henisz W.J., Swaminathan A. [1]) и методов его картирования (Schneider M.R. [2]), в части детерминирования базы количественных показателей для выделения институтов и их пропорций. В практической плоскости предложенные индикаторы могут быть использованы в исследовании институциональной структуры отраслей высокотехнологичного сектора промышленности. 


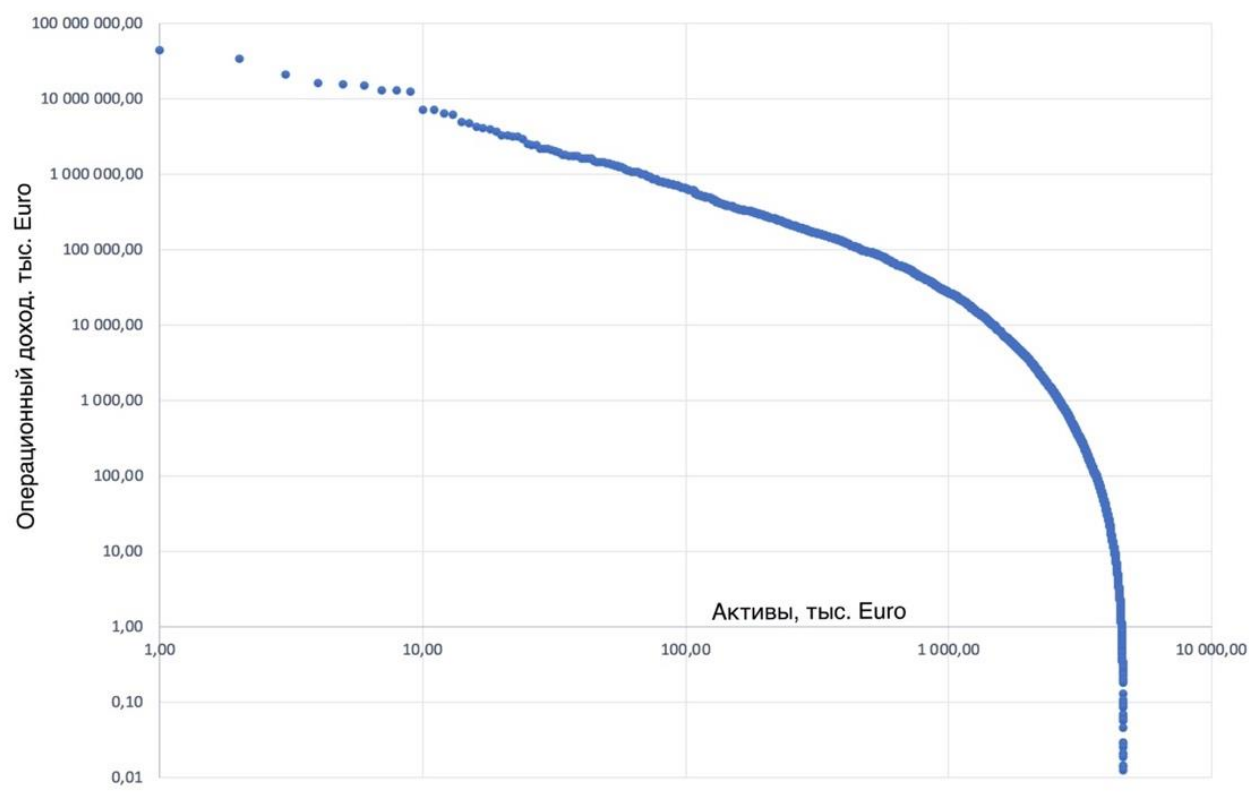

Рис. 3. Поле корреляции показателей величины активов и операционного дохода

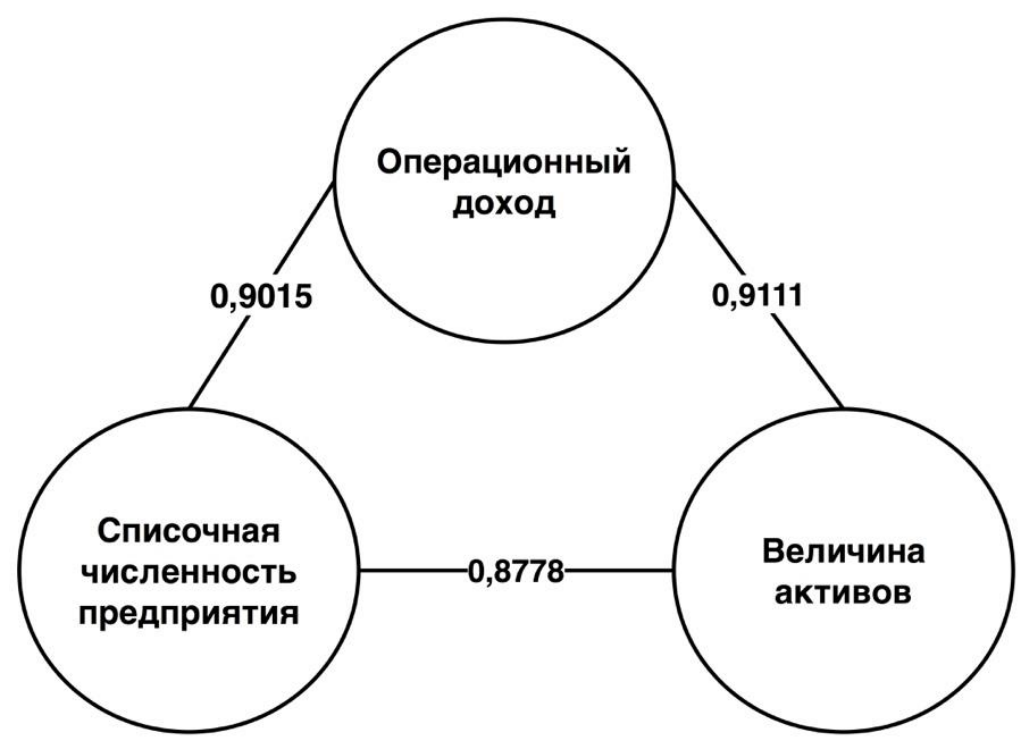

Puc. 4. Структура взаимосвязанных показателей роста высокотехнологичных отраслей. Обозн.: корреляции табл. 2

\section{Библиографический список}

1. Henisz, W. J., Swaminathan, A. Institutions and international business. Journal of International Business Studies, 2008. 39(4): 537-539.

2. Schneider, M. R., Schulze-Bentrop, C., Paunescu, M. Mapping the institutional capital of high-tech firms: A fuzzy-set analysis of capitalist variety and export performance. Journal of International Business Studies, 2010.

3. Dopfer, $K$. The Origins of Meso Economics Schumpeter's Legacy. In the Papers on Economics and Evolution. Jena, Germany: Evolutionary Economics Group 2006.

4. Paunescu, M., Schneider, M. More on testing the varieties of capitalism. Schmollers Jahrbuch: Zeitschrift fu" $\mathrm{r}$ Wirtschafts- und Sozialwissenschaften, 2005, 125(2): 323-325.

5. Dixon, M., Roscigno, V. J., Hodson, R. Unions, solidarity, and striking. Social Forces, 2004, 83(1): 3-33. 
6. Kleiner, M. M. Intensity of management resistance: Understanding the decline of unionization in the private sector. Journal of Labor Research, 2004 22(3): 519-540.

7. Boyer, $R$. New growth regimes, but still institutional diversity. Socio-Economic Review, 2004, 2(1): 1-32.

8. Jackson, G., Deeg, R. Comparing capitalisms: Understanding institutional diversity and its implications for international business. Journal of International Business Studies, 2008. 39(4): 540-561.

9. Клейнер Г.Б. Эволюция институциональных систем. Издательство: Наука, 2004.

10. Волынский А.И. Мезоуровень как объект исследования в экономической литературе современной России Journal of institutional studies (Журнал институциональных исследований) Том 9, o 3. 2017.

11. Гареев Т.Р. Институты и экономическое развитие на субрегиональном (мезо-) уровне // Общественные науки и современность, № 5, 2010. с. 45-58.

12. Марков Л.С., Ягольницер М.А. Мезоэкономические системы: проблемы типологии // Регион: экономика и социология, № 1, 2008. с. 18-44.

13. Кирдина С.Г. Методологический институционализм и мезоуровень социального анализа // СОЦИС, № 12 , 2015, с. 51-59.

14. Ореховский П.А. Структура поля экономического знания: возможности и пределы общественных дискуссий // Общественные науки и современность, № 1, 2015, с. 5-23.

15. Гасанов Э. А., Бойко Т.С. и Фролова Н.С. Основные направления теории инновационной мезоэкономики // Экономика и предпринимательство, № 12-2 (77-2), 2016, с. 211-216.

16. Тишков С.В. Управление формированием и развитием инновационных подсистем на мезоуровне // Вопросы управления, N3 (15), 2015, с. 158-165. 